\title{
Ultrasound-assisted Extraction of Fe (III) from Wet-process Phosphoric Acid
}

\author{
Xingbin LV, Daijun LIU, Junyi JI, Jianjun CHEN* and Tao YANG \\ Department of Chemical Engineering, Sichuan University, Chengdu, Sichuan, 610065, People' Republic of \\ China
}

(Received June 6, 2016; Accepted September 28, 2016)

\begin{abstract}
An ultrasound-assisted extraction (UAE) method was developed for the extraction of Fe (III) from wet-process phosphoric acid with di (2-ethylhexyl) phosphoric acid (D2EHPA). The influences of UAE parameters, including ultrasonic power, extraction time, concentration of D2EHPA and extraction temperature, were systematically studied. The response surface methodology, a statistical technique, was used to obtain the optimal conditions and evaluate the significance of variables affecting the extraction efficiency of the UAE. It was found that ultrasound could markedly improve the extraction rate of Fe (III) with D2EHPA, the largest improvement is up to 7 times compared with the traditional solvent extraction method. However, the extraction equilibrium of the extraction system was not affected by ultrasound. It is believed that the cavitation effect of ultrasound, along with the increased interfacial surface area, contribute to the enhancement of the extraction rate.
\end{abstract}

\section{Introduction}

About $90 \%$ of the phosphoric acid produced worldwide is obtained from the low-cost and low energy consumption wet-process phosphoric acid (WPA) process, which uses sulfuric acid digestion [1]. However, WPA is almost entirely used to produce fertilizer, because the various impurities in WPA interfere with its application in other fields. With the development of modern science and technology, the demand of high purity phosphoric acid is increasing. High purity phosphoric acid is usually used in food additives, detergents, electronic grade phosphates and other high value-added fine chemical products. Thus, WPA has to be further purified in order to extend its application fields [2-4]. Ferric iron is one of the most troublesome impurities, and it can increase the viscosity of the WPA, thus decreasing its quality. In the published literature, several purification methods have been developed to remove ferric iron from WPA, such as precipitation [5], adsorption [6-7], membrane separation [8], solvent extraction [9-12], ion-exchange and so on. Nowadays, solvent extraction has become the main purification method to remove ferric iron from WPA. However, there are some limitations in the conventional solvent extraction method (CE), such as a long extraction time and high organic solvent consumption. Therefore, improvements in the extraction rate is the key to solve this problem.

As a mass transfer enhancement technology, ultrasound is widely applied in chemical engineering, the food industry and other fields. It was reported that ultrasound can significantly improve both dissolution 
(reaction) rates and yields of product because of the cavitation effect, as well as the mechanical and heat effects of ultrasound [13-16]. Several studies on ultrasound-assisted extraction have been reported for metallic liquid-liquid extraction systems [17-18]. The results showed that ultrasound can increase the interfacial area between the two phases and significantly speed up the extraction rate, but the chemical reaction mechanism and the extraction equilibrium remain constant. As a typical example, Pesic B [19] et al. found that ultrasound-assisted extraction was an effective technique for reducing the time for nickel extraction from $\mathrm{KNO}_{3}$. However, to the best of our knowledge, no study of ultrasound-assisted extraction of Fe (III) from WPA has yet been reported.

In this paper, an ultrasound-assisted extraction technique is used to remove Fe (III) from WPA. The effect of extraction conditions on the extraction efficiency were investigated in detail, and the extraction conditions were optimized using the response surface methodology (RSM).

\section{Experimental}

\subsection{Chemicals and materials}

The extractant di (2-ethylhexyl) phosphoric acid (abbreviated as D2EHPA or simply HA) was obtained from Luoyang Zhongda Chemical Co. (Henan, China). Kerosene was provided by Zhongcui Chemical Co. (Sichuan, China). D2EHPA (purity $\geqslant 95 \%$ ) was used without any further purification, and kerosene was distilled to collect the $200-260{ }^{\circ} \mathrm{C}$ fraction (colorless and aliphatic in nature). It was used as the diluent to obtain the desired concentration of D2EHPA. The required initial concentration of Fe (III) $(0.04 \mathrm{~mol} / \mathrm{L})$ was produced by dissolving ferric sulfate in phosphoric acid $\left(\mathrm{P}_{2} \mathrm{O}_{5}=20 \%\right)$. Ferric sulfate, phosphoric acid, 1 , 10-phenanthroline and hydroxylammonium chloride were of analytical reagent and supplied by Kelong Chemical Co. (Sichuan, China).

\subsection{Ultrasound-assisted extraction}

Ultrasound-assisted extraction was carried out using an ultrasonic probe processor (Scientz-IID, Ningbo scientz biotechnology Co., Ningbo, China), which had a maximum input power of $950 \mathrm{~W}$ and an operating frequency of $20 \mathrm{kHz}$. Equal volumes $(40 \mathrm{~mL})$ of D2EHPA and aqueous solutions containing Fe (III) ions (0.04 $\mathrm{mol} / \mathrm{L}$ ) were added to a jacketed beaker (inner diameter, $50 \mathrm{~mm}$; height, $60 \mathrm{~mm}$ ), and then directly treated at different UAE parameters by using a probe microtip (diameter $10 \mathrm{~mm}$ ) immersed $1 \mathrm{~cm}$ into the solution. The ultrasonic pulse sequence was $2 \mathrm{~s}$ on and $2 \mathrm{~s}$ off, respectively. The temperature of the system was controlled through circulating external water from a thermostatic water bath. The schematic drawing of the apparatus is shown in Figure 1. After ultrasound, the beaker was removed from the apparatus and the mixture was filtered through a $0.22 \mu \mathrm{m}$ microporous membrane under vacuum. Finally, after phase separation, the volume of aqueous phase and the concentration of Fe (III) therein were measured. 




Figure 1. Schematic representation of the apparatus for the ultrasound-assisted extraction.

For comparison, conventional solvent extraction was conducted in a water bath temperature oscillator under the same conditions as those used in the UAE experiments but without ultrasound. The shaking speed was held constant at $200 \mathrm{rpm}$.

\subsection{Experimental design}

First, the effects of ultrasonic power (W), extraction time (min), extractant concentration $(\mathrm{mol} / \mathrm{L})$ and extraction temperature $\left({ }^{\circ} \mathrm{C}\right)$ on the extraction yield under ultrasound treatment were investigated, respectively. The range of variables and the optimal parameters are listed as follows in Table 1.

Table 1. Test of parameters.

\begin{tabular}{|c|c|c|}
\hline Variables & Range researched & Optimal parameters \\
\hline Ultrasonic power $(\mathrm{W})$ & $47.5-285$ & 47.5 \\
\hline Extraction time $(\mathrm{min})$ & $0.3-12$ & 3 \\
\hline Extractant concentration $(\mathrm{mol} / \mathrm{L})$ & $0.5-2.5$ & 2 \\
\hline Extraction temperature $\left({ }^{\circ} \mathrm{C}\right)$ & $20-45$ & 20 \\
\hline
\end{tabular}

The extraction of $\mathrm{Fe}$ (III) from WPA was investigated and optimized by using a response surface methodology (RSM). A Box-Behnken design (BBD) was adopted to assess the effects of extraction time (A), extractant concentration (B), and extraction temperature (C) and their interaction effects at three equidistant levels [20]. The variables and their levels, as well as both coded values and natural values were investigated in this study and displayed in Table 2. Given the consequences of the preliminary single factor, the ranges of three independent variables of the extraction process were controlled. The BBD included 17 experimental runs and 5 replicates of the central points. The experiments were performed so as to decrease the effect of unexpected variability in the observed response from extraneous factors. Table 3 exhibits the design matrix for the experiments and the regression model proposed for response is given by the following equation:

$$
Y=\beta_{0}+\sum_{i=1}^{3} \beta_{i} X_{i}+\sum_{i=1}^{3} \beta_{i i} X_{i}^{2}+\sum_{i<j}^{3} \beta_{i j} X_{i} X_{j}
$$

where $Y$ is the predicted response, $\beta_{0}$, which is $(0,0,0)$, is the value of the fixed response at the central point of the experiment, $\beta_{\mathrm{i},} \beta_{\mathrm{ii}}$ and $\beta_{\mathrm{ij}}$ are the linear, quadratic and interactive coefficients, respectively. $X_{\mathrm{i}}$ and $X_{\mathrm{j}}$ are 
independent variables. Analysis of variance (ANOVA) was carried out to identify the adequacy of the developed model and the statistical significance of the regression coefficients.

Table 2. Variables and their levels employed in the BBD.

\begin{tabular}{|c|c|c|c|c|}
\hline \multirow{2}{*}{ Variables } & \multirow{2}{*}{ Symbol } & \multicolumn{3}{|c|}{ Coded levels } \\
\cline { 3 - 5 } & & -1 & 0 & 1 \\
\cline { 3 - 5 } & & \multicolumn{3}{|c|}{ Natural levels } \\
\hline Extraction time(min) & $\mathrm{A}$ & 2 & 3 & 4 \\
\hline Extractant concentration(mol/L) & $\mathrm{B}$ & 1.5 & 2 & 2.5 \\
\hline Extraction temperature $\left({ }^{\circ} \mathrm{C}\right)$ & $\mathrm{C}$ & 20 & 25 & 30 \\
\hline
\end{tabular}

Table 3. The BBD arrangement for the extraction of Fe (III) and the observed responses for extraction yield.

\begin{tabular}{|c|c|c|c|c|}
\hline Run & $\mathrm{A}(\mathrm{min})$ & $\mathrm{B}(\mathrm{mol} / \mathrm{L})$ & $\mathrm{C}\left({ }^{\circ} \mathrm{C}\right)$ & $\mathrm{E}(\%)$ \\
\hline 1 & 4 & 2.5 & 25 & 77.43 \\
\hline 2 & 2 & 2 & 20 & 64.44 \\
\hline 3 & 3 & 2 & 25 & 68.01 \\
\hline 4 & 3 & 2.5 & 30 & 69.14 \\
\hline 5 & 3 & 2.5 & 20 & 76.51 \\
\hline 6 & 4 & 1.5 & 25 & 59.44 \\
\hline 7 & 2 & 2.5 & 25 & 62.01 \\
\hline 8 & 2 & 2 & 30 & 58.37 \\
\hline 9 & 3 & 1.5 & 30 & 55.83 \\
\hline 10 & 3 & 1.5 & 20 & 62.93 \\
\hline 11 & 3 & 2 & 25 & 69.5 \\
\hline 12 & 3 & 2 & 25 & 69.5 \\
\hline 13 & 3 & 2 & 25 & 69.89 \\
\hline 14 & 2 & 1.5 & 25 & 56.87 \\
\hline 15 & 4 & 2 & 20 & 74.76 \\
\hline 16 & 3 & 2 & 25 & 70.12 \\
\hline 17 & 4 & 2 & 30 & 70.63 \\
\hline
\end{tabular}

\subsection{Determination of $\mathbf{F e}$ (III) in solution}

The concentration of $\mathrm{Fe}$ (III) in the aqueous phase was determined by the 1, 10-phenanthroline method after reduction to $\mathrm{Fe}$ (II) with hydroxylammonium chloride [21]. The standard curve method was used for the quantification of iron (the standard equation $C=0.19151 A-0.00313, R^{2}=0.99994$, where $C$ is the concentration of the iron ion, $A$ is the solution absorbance, and $R$ is the correlation coefficient). In all the experiments, each data point represents a mean value of three independent measurements. The extraction yield was calculated based on the following equation: 


$$
E(\%)=\frac{C_{0} V_{0}-C_{e} V_{e}}{C_{0} V_{0}} \times 100 \%
$$

where $E$ is the extraction efficiency, $C_{0}$ is the initial concentration of $\mathrm{Fe}$ (III) in the aqueous phase, $C_{\mathrm{e}}$ is the concentration of $\mathrm{Fe}$ (III) remaining in the aqueous phase, and $V_{0}$ and $V_{\mathrm{e}}$ are the volumes of the initial aqueous phase and raffinate phase, respectively.

\section{Results and discussion}

\subsection{Effect of ultrasonic power on the extraction process}

The effect of ultrasonic power on the extraction yield of Fe (III) from WPA with $1 \mathrm{~mol} / \mathrm{L}$ D2EHPA at a fixed extraction time of $2 \mathrm{~min}$ and $20^{\circ} \mathrm{C}$ has been investigated and is shown in Figure 2. The extraction yield changes slightly under different ultrasonic power levels. This may be due to the large quantity of cavitation micro-bubbles generated by the ultrasound treatment, which can increase the contact interface between the two phases and facilitate the transfer of Fe (III) ions into the organic phase. Due to the high efficiency of this process, ultrasonic power may have no obviously effect to the extraction rate. On the basis of energy consumption, $47.5 \mathrm{~W}$ was selected as the optimum ultrasound power.



Figure 2. Effect of ultrasonic power on the extraction yield of Fe (III) from WPA.

Extraction conditions under ultrasound: extraction time, $2 \mathrm{~min}$; D2EHPA concentration, $1 \mathrm{~mol} / \mathrm{L}$; extraction temperature, $20^{\circ} \mathrm{C}$.

\subsection{Effect of extraction time on the extraction process}

The effect of extraction time using UAE and CE methods on the extraction yields of Fe (III) from wet-process phosphoric acid are shown in Figure 3. The UAE extraction experiments were carried out using 1 $\mathrm{mol} / \mathrm{L} \mathrm{D2EHPA}$ at a power of $47.5 \mathrm{~W}$ and a temperature of $20^{\circ} \mathrm{C}$. Comparing the two extraction techniques at different treatment times, it was found that the extraction yield was highly time-dependent for both techniques. On the other hand, the same trend could also be observed in the extraction yields versus time curves: the extraction yield first increased significantly with increasing extraction time, and then increased slowly for 
longer extraction times after the extraction yield reached $45 \%$. However, the extraction yield of the ultrasound-assisted extraction method was higher than that using the conventional extraction method. The yield (45\%) of the conventional extraction could be achieved after $20 \mathrm{~min}$, but only after $3 \mathrm{~min}$ for the ultrasound-assisted extraction. The ultrasonic extraction rate was 6 times higher than that of the conventional solvent extraction method at similar extraction yields. This result indicates that the ultrasound-assisted extraction could efficiently improve the extraction efficiency in contrast to the conventional extraction method.

By virtue of the investigation, the cavitation effect of ultrasound, along with other mechanical effects which were generated by this process, such as microjets, shock waves, could accelerate the degree of turbulence and thus further enhance mass transfer between the extractant and Fe (III) irons. Furthermore, ultrasound might reduce the time to the establishment of equilibrium for the extraction reaction, but the ultrasound had no effect on the final chemical equilibrium. To sum up, the use of ultrasound made a significant impact on the extraction yield. Yet when the extraction time was above $3 \mathrm{~min}$, the extraction yields had barely increased. Hence, 3 min was selected in the following experiments.

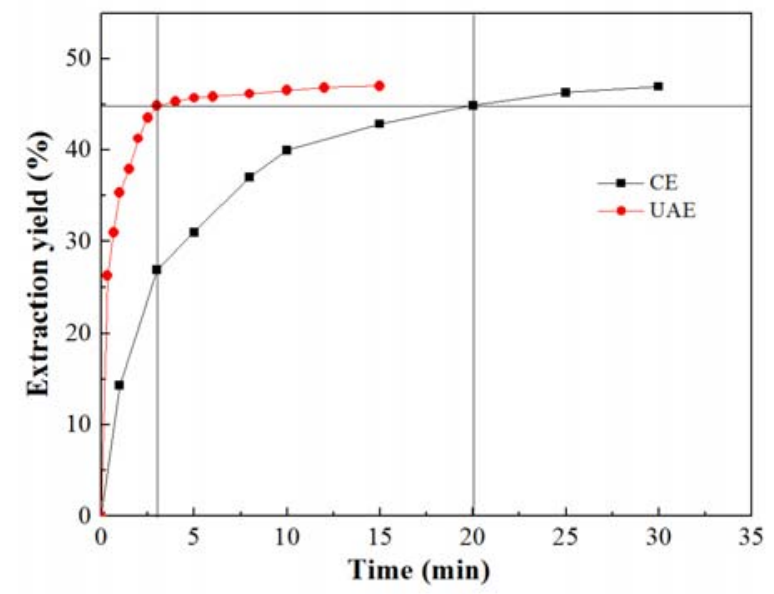

Figure 3. Effect of extraction time on the extraction yield of Fe (III) under UAE and CE.

The UAE conditions were: ultrasonic power, $47.5 \mathrm{~W}$; D2EHPA concentration, $1 \mathrm{~mol} / \mathrm{L}$; extraction temperature, $20^{\circ} \mathrm{C}$.

\subsection{Effect of extractant concentration on the extraction process}

The effect of varying concentration of D2EHPA for the extraction of Fe (III) from WPA has been studied. Other fixed conditions were as follows: ultrasonic power, $47.5 \mathrm{~W}$; extraction time, $3 \mathrm{~min}$; extraction temperature, $20^{\circ} \mathrm{C}$. From the results illustrated in Figure 4, the extraction yields increase significantly with the extractant concentration from 0.5 to $2 \mathrm{~mol} / \mathrm{L}$. After that, the rate increase decreases and only a little increase was observed from 2 to $2.5 \mathrm{~mol} / \mathrm{L}$. This was probably because the higher extractant concentration causes a greater concentration difference, which further accelerates mass transfer and facilitates the iron ion diffusion into the organic phase. Therefore, $2 \mathrm{~mol} / \mathrm{L}$ was used as the optimal extractant concentration in the following extraction experiments. 
In addition, the results showed that the extraction efficiency of the ultrasound-assisted extraction method was greater than the conventional extraction method. On the other hand, the difference between the extraction yields of the two extraction techniques increased with the increasing concentration of D2EHPA in this work. This phenomenon indicated that the greater the concentration of D2EHPA used, the better was the effect of the ultrasound-assisted extraction technology.

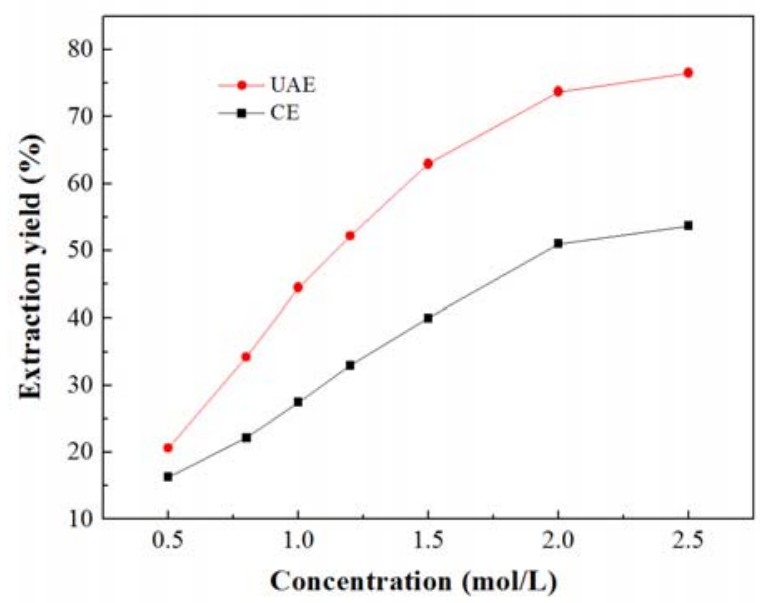

Figure 4. Effect of extractant concentration on the extraction yield of Fe (III) from WPA.

Extraction conditions under ultrasound: ultrasonic power, $47.5 \mathrm{~W}$; extraction time, $3 \mathrm{~min}$; extraction temperature, $20^{\circ} \mathrm{C}$.

\subsection{Effect of extraction temperature on the extraction process}

Because of the significance of the temperature during the extraction process, its influence on ultrasound-assisted extraction was also evaluated and is presented in Figure 5. Other conditions were: ultrasonic power of $47.5 \mathrm{~W}$, extraction time of $3 \mathrm{~min}$, and $2 \mathrm{~mol} / \mathrm{L}$ D2EHPA. Obviously, the extraction efficiency of the UAE technique was higher than that of the conventional extraction method at the same temperature. However, a negative effect on the extraction yields was observed with an increase in the extraction temperature for both of the two extraction techniques. This phenomenon might be explained as follows: (a) the extraction mechanism for Fe (III) by D2EHPA from phosphoric acid could be expressed as [22-23]:

$$
\begin{gathered}
\mathrm{HA}+\mathrm{HA} \rightarrow(\mathrm{HA})_{2} \\
\mathrm{Fe}^{3+}+3(\mathrm{HA})_{2} \rightarrow \mathrm{Fe}\left(\mathrm{HA}_{2}\right)_{3}+3 \mathrm{H}^{+}
\end{gathered}
$$

For an exothermic reaction, the extraction yields reduce with the increase of temperature. This phenomenon was also observed by D.K. Singh et al. [11], who found that a higher temperature did not lead to a higher extraction yield. (b) On the other hand, the decreased rate of the UAE technique was faster than that of the conventional extraction method, which might be attributed to the thermal effect of ultrasound. Although the increase of temperature may accelerate thermal activity which promoted the Fe (III) ions transfer into the 
organic phase, a higher temperature resulted in the decrease of cavitation intensity and the efficiency of collapsing bubbles [24].

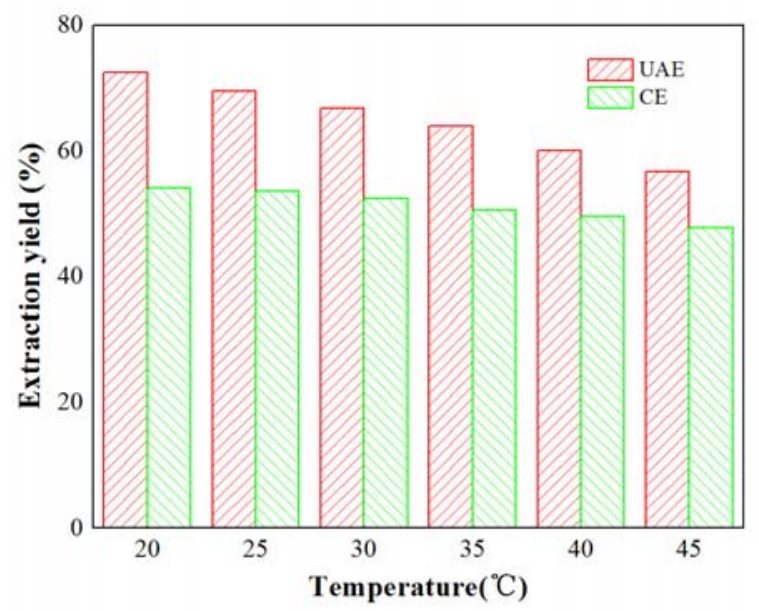

Figure 5. Effect of temperature on the extraction yield of Fe (III) from WPA.

Extraction conditions under ultrasound: ultrasonic power, $47.5 \mathrm{~W}$; extraction time, $3 \mathrm{~min}$; D2EHPA concentration, $2 \mathrm{~mol} / \mathrm{L}$.

\subsection{Optimization of extraction conditions}

Obtaining the optimal conditions for ultrasound-assisted extraction of $\mathrm{Fe}$ (III) from wet-process phosphoric acid would be beneficial to the development of the UAE process in industry. Based on the single factor investigations, the optimal levels of the significant factors (extraction time, extractant concentration and temperature) and their interaction effects on the extraction yields were explored by a BBD of the RSM. The experimental conditions and the corresponding experimental data are displayed in Table 3 . The predicted model can be described by

$$
\begin{gathered}
Y(\%)=15.06+3.35 A+45.22 B-0.66 C+6.42 A B+0.97 A C \\
-0.03 B C-2.26 A^{2}-12.83 B^{2}-0.04 C^{2}
\end{gathered}
$$

where $Y$ is the predicted extraction yield (\%); $A, B$ and $C$ are extraction time, extractant concentration and temperature, respectively. Positive coefficients indicate a favorable effect on extraction yield, while negative coefficients indicate an unfavorable effect on extraction yield [20]. Thus, from Eq. (5), it is demonstrated that there was a positive influence caused by both ultrasonic time and extractant concentration on extraction yield, whereas the effect of extraction temperature was the reverse, which corresponded with the results of the previous single factor experiment. 
Table 4. ANOVA for extraction yield from BBD experiments.

\begin{tabular}{|c|c|c|c|c|c|}
\hline Source & $\begin{array}{c}\text { Sum of } \\
\text { squares }\end{array}$ & $\mathrm{d} f$ & $\begin{array}{c}\text { Mean } \\
\text { square }\end{array}$ & $F$ value & $\begin{array}{c}\text { P Value } \\
\text { prob }<F\end{array}$ \\
\hline Model & 705.68 & 9 & 78.41 & 58.45 & $<0.0001$ \\
\hline A- time & 205.74 & 1 & 205.74 & 153.37 & $<0.0001$ \\
\hline B- concentration & 312.75 & 1 & 312.75 & 233.14 & $<0.0001$ \\
\hline C- temperature & 76.08 & 1 & 76.08 & 56.71 & 0.0001 \\
\hline $\mathrm{AB}$ & 41.28 & 1 & 41.28 & 30.77 & 0.0009 \\
\hline $\mathrm{AC}$ & 0.94 & 1 & 0.94 & 0.7 & 0.43 \\
\hline $\mathrm{BC}$ & 0.018 & 1 & 0.018 & 0.014 & 0.9105 \\
\hline $\mathrm{A}^{2}$ & 21.5 & 1 & 21.5 & 16.02 & 0.0052 \\
\hline $\mathrm{B}^{2}$ & 43.3 & 1 & 43.3 & 32.28 & 0.0007 \\
\hline $\mathrm{C}^{2}$ & 0.038 & 1 & 0.038 & 0.028 & 0.8718 \\
\hline Residual & 9.39 & 7 & 1.34 & & \\
\hline Lack of Fit & 6.68 & 3 & 2.23 & 3.29 & 0.1403 \\
\hline Pure Error & 2.71 & 4 & 0.68 & & \\
\hline Cor Total & 715.07 & 16 & & & \\
\hline
\end{tabular}

The analysis of variances for the BBD experiments is shown in Table 4. Two important indicators for ANOVA were the $F$-value and the $p$ value. The F-value $(58.45)$ and $p$ value $(p<0.0001)$ show the significance of the model. Moreover, ANOVA for extraction yield also gave fairly large determination coefficients $\left(\mathrm{R}^{2}=98.69\right)$. Additionally, the F-value and $\mathrm{p}$ value of the lack of fit were 3.29 and 0.1403 , respectively. Based on the above values, it is suggested that the mathematical model was quite credible for extraction yield in the present study.

The significance of each coefficient was determined using the Student's F-test and p-value and the results are shown in Table 4 . The p-value indicates the interaction strength between each independent variable [25]. These results clearly show that the linear coefficients $(A, B, C)$, the quadratic term coefficients $\left(A^{2}, B^{2}\right)$, and an interactive term coefficients $(\mathrm{AB})$ are significant at small $\mathrm{p}$ values $(\mathrm{p}<0.05)$. The other term coefficients are not significant.

According to Eq. (5), three-dimensional surface plots of the effects of $\mathrm{AB}, \mathrm{AC}$, and $\mathrm{BC}$ on extraction yields were constructed in Figure 6- Figure8. In Figure 6, it can be observed that both the extraction time and extractant concentration significantly influenced the extraction yield of $\mathrm{Fe}$ (III). A positive effect was produced by the extraction time and extractant concentration. The extraction yield increased as both parameters increased. The effects of extraction time, extraction temperature, and their interactions on extraction yield are presented in Figure 7. The extraction yields increased slowly following the increase in extraction time at a fixed extraction temperature. However, the increase in extraction temperature at a fixed extraction time gave rise to a gradual decrease in extraction yields. In Figure 8, the higher the extractant concentration, the lower the extraction temperature, the higher extraction yield is obtained. 


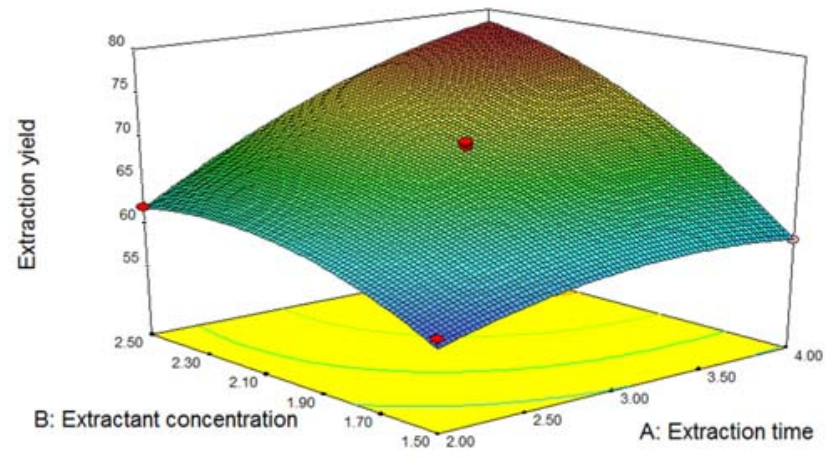

Figure 6. Response surface plot showing the effect of extraction time and extractant concentration on the extraction yield of Fe (III) from WPA.

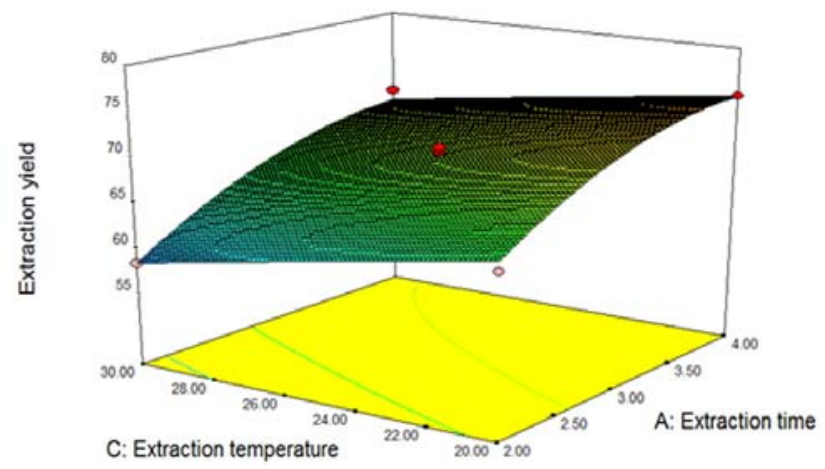

Figure 7. Response surface plot showing the effect of extraction time and extraction temperature on the extraction yield of Fe (III) from WPA.



Figure 8. Response surface plot showing the effect of extractant concentration and extraction temperature on the extraction yield of $\mathrm{Fe}$ (III) from WPA. 
Through the analysis for Eq. (5), the optimally extraction conditions using the model were as follows: extraction time, $3.68 \mathrm{~min}$; extractant concentration, $2.36 \mathrm{~mol} / \mathrm{L}$; and extraction temperature, $20.14{ }^{\circ} \mathrm{C}$.Under the optimal extraction conditions, the model predicts a maximum extraction yield of $78.89 \%$. To verify the results of the BBD experiments as well as confirm the reliability of this model, experiments were made with the above optimized extraction conditions. A mean value of $79.01 \%$ (Table 5) was obtained, slightly higher than the predicted value. The consistency of the experiment result and the predicted value proved the utility of this model, also further explained that optimizing the RSM parameters was very successful.

Table 5. Comparison of predicted and experimental values of the response under those conditions.

\begin{tabular}{|c|c|c|c|c|}
\hline \multicolumn{3}{|c|}{ Optimum conditions } & \multicolumn{2}{c|}{ Extraction yield (\%) } \\
\hline $\begin{array}{c}\text { Extraction } \\
\text { Time }(\mathrm{min})\end{array}$ & $\begin{array}{c}\text { Extractant } \\
\text { concentration } \\
(\mathrm{mol} / \mathrm{L})\end{array}$ & $\begin{array}{c}\text { Extraction } \\
\text { temperature }\left({ }^{\circ} \mathrm{C}\right)\end{array}$ & Predicted value & $\begin{array}{c}\text { Experimental } \\
\text { value }\end{array}$ \\
\hline 3.68 & 2.36 & 20.14 & 78.89 & $79.01^{\mathrm{a}}$ \\
\hline
\end{tabular}

a Mean \pm SD $(n=3)$.

\section{Conclusion}

In this study, an ultrasound-assisted extraction process for the extraction of $\mathrm{Fe}$ (III) ions from wet-process phosphoric acid was developed. The effects of various factors, including the ultrasonic power, extraction time, extractant concentration and extraction temperature were systematically investigated. The extraction rate was 6 times higher than that for the traditional extraction method. Based on the results of single factor experiments, a Box-Behnken design for response surface methodology was applied to determine the optimal experimental conditions. The ultrasound-assisted extraction extraction efficiency of Fe (III) reached 79.01\% under the following optimum conditions: extraction time, $3.68 \mathrm{~min}$; extractant concentration, 2.36 $\mathrm{mol} / \mathrm{L}$; and extraction temperature, $20.14{ }^{\circ} \mathrm{C}$. On the basis of the ANOVA statistical analysis, the extractant concentration for the ultrasound-assisted extraction was the most significant parameter, following by extraction time and extraction temperature. As the ultrasound-assisted extraction increases mass transfer for any two phase systems, the UAE method could be easily extended to other extraction systems for higher efficiency.

\section{References}

1) J. Yu, D.J. Liu, Chem. Eng. Res. Des., 88, 712-717 (2010).

2) X.H. Jia, J. Li, Y. Jin, J.H. Luo, B.M. Wang, C.L. Ma, Solvent Extr. Res. Dev. Jpn., 20, 183-195 (2013)

3) H. Ahmed, H. Diamonta, C. Chaker, R. Abdelhamid, Sep. Purif. Technol., 55, 212-216 (2007).

4) N.S. Awwad, Y.A. El-Nadi, M.M. Hamed, Chem. Eng. Process, 74, 69-74 (2013).

5) A.A. El-Asmy, H.M. Serag, M.A. Mahdyb, M.I. Aminb, Sep. Purif. Technol., 61, 287-292 (2008).

6) L. Monser, M. Ben Amor, M. Ksibi, Chem. Eng. Process, 38, 267-271 (1999).

7) A.A.M. Daifullah, N.S. Awwad, S.A. El-Reefy, Chem. Eng. Process, 43, 193-201 (2004). 
8) M.P. Gonzalez, R. Navarro, I. Saucedo, M. Avila, J. Revilla, Ch. Bouchard, Desalination, 147, 315-320 (2002).

9) S. Meles, M.V. Prostenik, Polyhedron, 3, 615-617 (1984).

10) M.I. El-Khaiary, Chem. Eng. Technol., 20, 338-341 (1997).

11) D.K. Singh, K.K. Yadav, H. Singh, Sep. Sci. Technol., 48, 1556-1564 (2013).

12) Y. Jin, Y.J. Ma, Y.L. Weng, X.H. Jia, J. Li, J. Ind. Eng. Chem., 20, 3446-3452 (2014).

13) K.M. Swamy, K.L. Narayana, Ultrason. Sonochem., 8, 341-346 (2001).

14) H. Li, Z.H. Zhang, S.P. Tang, Y.N. Li, Y.K. Zhang, Ultrason. Sonochem., 15, 339-343 (2008).

15) T.S. Awad, H.A. Moharram, O.E. Shaltout, D. Aske, M.M. Youssef. Food Res Int., 48, 410-427 (2012).

16) T.J. Mason, F. Chemat, M. Vinatoru, Curr. Org. Chem., 15, 237-247 (2011).

17) B. Pesic, T. Zhou, J. Miner. Met. Mater. Soc., 41, $42-45$ (1989).

18) F. Flisak, A. Perna, Ultrasonics, 15, 27-29 (1977).

19) B. Pesic, T. Zhou, Metall. Trans. B, 23B, 13-22 (1992).

20) A.B. Solanki, J.R. Parikh, R.H. Parikh, AAPS Pharm. Sci. Technol., 8, 1-7 (2007).

21) A.I. Vogel, A Textbook of Quantitative Chemical Analysis, 5th edn. ELBS, Longman, England, 1989, p.690.

22) S. Nishihama, T. Hiral, I. Komasawa, Ind. Eng. Chem. Res., 38, 4850-4856 (1999).

23) A. Mellah, D. Benachour, Chem. Eng. Process, 45, 684-690 (2006).

24) Y. Xu, S.Y. Pan, Ultrason. Sonochem., 20, 1026-1032 (2013).

25) F. Wang, X.Y. Guo, D.N. Zhang, Y. Wu, T. Wu, Z.G. Chen, Ultrason. Sonochem., 24, 36-42 (2015). 